\title{
BRON Jr, Michal; GUIMARÃES, Paula e CASTRO, Rui Vieira de (Eds.). (2009). The State, Civil Society and the Citizen - Exploring Relationships in the Field of Adult Education in Europe. Frankfurt am Main: Peter Lang (229 páginas).
}

Este é um livro que junta à qualidade e rigor científicos, habituais da colecção European Studies in Lifelong Learning and Adult Learning Research (Estudos Europeus em Investigação sobre Aprendizagem ao Longo da Vida e Aprendizagem dos Adultos) que a ESREA - European Society for Research on the Education of Adults (Sociedade Europeia de Investigação em Educação de Adultos) activamente promove, todo um conjunto de problematizações, abrangentes e criticamente orientadas, incontornáveis para quem se propuser desconstruir e desmistificar o mandato, politicamente hegemónico, atribuído hoje ao sector da Educação e Formação de Adultos.

O livro resulta da selecção (com revisão de pares) dos textos fundamentais apresentados na Conferência da Active Democratic Citizenship and Adult Learning Research Network (Rede Europeia de Investigação em Cidadania Activa Democrática e Aprendizagem nos Adultos), realizada em 2007, pela Unidade de Educação de Adultos na Universidade do Minho. Na introdução os editores apresentam a lógica de organização das três partes desta obra, que oferece, através de 12 artigos, um olhar múltiplo do campo da educação de adultos, alicerçado em interpretações propostas por 18 investigadores e educadores de distintos países europeus. Aqui o denominador comum é a leitura crítica da realidade social, na qual se redefiniu - Estado Providência, e a preocupação com o actual rumo dado, exogenamente, ao sector pelas políticas transnacionais de aprendizagem ao longo da vida, que abandonaram, no trato da questão social, os valores da justiça social, da solidariedade e do desenvolvimento social e pessoal dos cidadãos.

Por representarem, quanto a nós, uma meta-narrativa de nível políticofilosófico, os três textos da primeira parte situam o racional do livro. Fazem-no convergindo na ideia-chave de ser hoje necessário construir uma nova educação de adultos, agora radicalizada num projecto que afronte, e confronte, a lógica da globalização neoliberal em curso. Atribui-se assim, aos actores do campo, a responsabilidade e a oportunidade de participar 
activamente numa agenda que contribua para democratizar a democracia, valorizando o bem público comum e a garantia dos direitos sociais já adquiridos. Trilhando caminhos autónomos (que vão desde a ideia de cosmopoliticidade, de uma pedagogia cosmopolítica, ou de uma cidadania republicana e cívica), o que sobressai é a sofisticação teórica comum a estes autores (Crowther com Martin, Estevão e Barbosa), que está patente no diálogo que desenvolvem com a herança de autores já clássicos no pensamento social como são Gramsci, Freire e Archibugi. Ao contrário de Nylander, também ele autor de uma recensão crítica sobre esta Obra ${ }^{1}$, o mote deixado por este conjunto inicial de artigos não nos parece irrealista mas sim criador de sinergias que cada um, em latitudes diversas, pode directa ou indirectamente usar, como comprovam, no nosso entender, precisamente os testemunhos e dados empíricos das várias investigações apresentadas nos artigos da segunda e terceira partes do livro.

Os cinco artigos da segunda parte focam, a partir de pontos de observação bem demarcados entre si, os discursos públicos das políticas actuais de educação de adultos. Ora, se qualquer política social, onde se situam as políticas educacionais por excelência, envolvem na sua governação uma inter-relação entre os níveis nacional, supranacional e subnacional, como temos vindo a sublinhar ${ }^{2}$, nada obsta a que se centralize a análise em um desses níveis por questões de inteligibilidade, mas sem se perder nesse exercício a lógica complexa que um estudo de sociologia política pressupõe. É isto precisamente que ocorre nesta parte do livro.

Assim, tanto Fejes como Walker escolhem tecer questionamentos a partir do trabalho de análise documental de textos oficiais, num caso produzidos pelo Ministério da Educação da Suécia, pelo Conselho da Europa e pela Comissão Europeia, e no outro caso produzidos pela OCDE. Fejes, baseado nos conceitos foucaultianos de governamentalidade e genealogia, tece considerações críticas à essência das relações de poder, evidenciando que o Estado neoliberal emergente, sem deixar de exercer o seu governo, o tornou, porém, menos visível ao distanciar-se das práticas directas de exercer a 'arte de governação'. Já Walker, operacionalizando uma 'análise crítica do discurso', percorre quatro textos oficiais recentes da OCDE, produzidos no influente âmbito dos seus educational think-tanks onde maioritariamente se fabricam os pressupostos do paradigma da aprendizagem ao longo da vida, lançando interrogações que, quanto a nós, poderiam ser mais arrojadas, mas 
que apesar de tudo possibilitam desafiar a retórica de uma pretensa nãoretórica (beyond rhetoric) disseminada aos vários Estados europeus pela OCDE.

De uma maneira relativamente encadeada com a temática de fundo destes dois artigos, seguem-se os textos de Guimarães e de Äberg. Ambos os autores investigam as políticas de educação de adultos a partir de um estudo de caso centrado no papel actual das organizações da sociedade civil, operando tanto a nível nacional como a nível transnacional, respectivamente. No seu artigo, Guimarães começa por fazer a análise diacrónica geral da agenda política para a construção do sector em Portugal, salientando os aspectos inovadores (e promissores face às restritas características deste cenário) do novo modelo pedagógico proposto pelo lançamento recente dos Cursos de Educação e Formação de Adultos, implementados segundo lógicas de partenariado, também elas inovadoras a nível nacional. A autora reflecte criticamente quer acerca do papel das entidades da sociedade civil, que de mediadoras passam a extensionistas da acção do Estado e que da intercolaboração passam para a inter-competição, quer acerca do papel do cidadão face às tensões e contradições existentes no actual discurso da aprendizagem ao longo da vida, que enquadra a lógica adaptativa desta nova oferta apresentada como emancipadora. Äberg, por seu turno, ilustra com o seu estudo, na nossa opinião, a educação de adultos cosmopolita de que se fala na primeira parte deste livro, apresentando alguns dos traços basilares da acção transfronteiriça das organizações não-governamentais, para o caso ilustrada através dos projectos de cooperação desenvolvidos entre a Associação dos Trabalhadores da Educação da Suécia e a Associação da Educação Aberta da Estónia. Assentes no modelo sueco das Folkbildning, o principal resultado dos projectos realizados entre estas associações viria a ser, segundo o autor, a disseminação além-fronteiras de métodos e pedagogias da educação de adultos de cariz emancipador e a consequente conscientização, geograficamente alargada, acerca da função social que a educação popular pode desempenhar no desenvolvimento da democracia e da cidadania activa.

No quinto e último capítulo desta parte do livro, Larsson reelabora os pressupostos tradicionais com que se caracteriza o conceito nórdico de Folkbildning, expandindo-o enquanto ideologia organizacional directamente implicada nas práticas organizacionais e nas práticas de liderança. Ora, 
sabendo-se que, a partir dos pressupostos do Folkbildning e dos círculos de estudos suecos, a forma como se faz a educação de adultos prevalece essencial face aos conteúdos que possam ser tratados, o autor identifica, com base nos dados de uma investigação exploratória por si conduzida, as três dimensões e as três funções que no seu argumento fundamentam que se pense este conceito/modelo enquanto ideologia organizacional potenciadora de um alargamento das práticas democráticas da participação cidadã.

De um certo modo, pelos desafios que deixa, este texto abre caminho para os questionamentos que se seguem nos quatro artigos que constituem a terceira e última parte deste livro, e que aborda mais particularmente as mudanças que ocorrem nos papéis, tempos e espaços da cidadania, que tanto aqui como no conjunto da obra é pensada como conceito em transição. Assim, ancorados num referencial teórico alinhado com o pensamento de Gransci, Bordiga e Freire, os autores do primeiro texto (Ramos, Fragoso e Florindo) reflectem acerca da importância dos novos movimentos sociais para tornar a cidadania numa 'cidadania participatória'. Fazem-no ancorados nos dados obtidos pelo estudo das 'Escolas de Cidadania e Participação' (resultantes de um acordo assinado entre a Câmara Municipal de Sevilha e o Instituto Paulo Freire de Espanha) que, segundo os autores, logram expandir a sociedade civil pelo alargamento às bases sociais marginalizadas de uma 'literacia participatória' que, na essência, usa a ferramenta do orçamento participativo para tornar a cidade mais humana e a educação mais libertadora. Pelo caminho entende-se, a partir daqui, que é a própria educação de adultos e os seus principais actores (educadores e educandos) que vão contrariando, contextualmente, a lógica de uma globalização neoliberal redutora do bemestar social.

O contexto português serve de cenário para os dois artigos que se seguem. O primeiro trata especialmente do papel da empresa na promoção da literacia em contexto profissional, apontando questionamentos que têm como inscrição de fundo os pressupostos da 'teoria social da literacia'. Aqui, Dionísio e Castro apresentam dados de um projecto bietápico que implicou começar por negociar com a fábrica as condições e ferramentas para a realização da investigação, para posteriormente co-construir em contexto laboral, usando como metodologia os círculos de leitura, um programa de intervenção educacional, de tipo experimental, que permitiu, de acordo com os autores, construir 'práticas endógenas de literacia' - saindo expostas, 
neste processo, as contradições pedagógicas com a lógica, mais instrumental, do 'conceito restrito de literacia' presente no discurso da indústria. Já o segundo texto, de Armando Loureiro e Artur Cristóvão, tendo também o contexto laboral como pano de fundo, debruça-se no trabalho quotidiano dos técnicos de um Centro de Educação e Formação de uma Associação de Desenvolvimento Local, para analisar o uso feito pelos agentes e organizações da sociedade civil (em que existem ofertas de educação de adultos) do discurso pedagógico oficialmente produzido pelo poder central. Recorrendo ao modelo proposto por Bernstein, os autores retiram dos dados obtidos que, embora seja visível uma dimensão importante em que ocorre sobretudo a reprodução do discurso hegemónico, há, não obstante, também lugar para a recontextualização local do mesmo. Neste caso opera, segundo os autores, uma 'epistemologia prática' que a partir do conhecimento local usa, embora de forma autolimitada pela dependência da actual lógica de candidaturas aos financiamentos, o seu 'espaço de manobra' face ao Estado e ao discurso pedagógico oficialmente difundido.

Evans é o autor do artigo com que encerra a terceira parte do livro, e na falta de um prólogo é, também, o seu derradeiro texto. Nele o autor explora os dados de uma investigação realizada através de uma abordagem biográfico-discursiva sobre narrativas de 'aprendizagem do eu', no contexto pós-Wende, isto é, no âmbito do impacto social do processo de reunificação da Alemanha. Com base nas práticas discursivas e representações manifestas numa amostra de docentes universitários da ex-Alemanha de leste, Evans perscruta as 'lacunas textuais' das suas histórias de vida, interpretando-as à luz das mudanças estruturais ocorridas nesta sociedade, que desvalorizaram o 'conhecimento biográfico' dos indivíduos inscritos em 'culturas educacionais' concretas, criando o que o autor designa de 'biografias de transição', onde a 'nova gramática social' das mentalidades colectivas impera, neste caso, obrigando os indivíduos a realinhar os termos sociológicos com que construíram as suas identidades até então, concebendo novas trajectórias em ruptura com o percurso anterior.

De um certo modo, esta é uma forma particular de encerrar um livro, que escolhe, como escrevem os editores na introdução, como temática transversal o tema da acelerada mudança (social, económica, política e educacional) que desde o final do século vinte vivemos globalmente. É particular, no nosso entender, porque neste artigo o analista social confronta- 
se com dados empíricos que relembram, ao leitor, o peso que a estrutura pode ter sobre a acção. No campo das actuais políticas transnacionais de aprendizagem ao longo da vida - que estão, como também referem os editores, a atribuir novas responsabilidades e deveres individuais ao cidadão, agora redefinido enquanto consumidor (para o caso de bens e serviços educacionais) - isto sugere, quanto a nós, que há uma importante tensão por resolver, que é ideológica na sua base: é que, se a 'educação não pode tudo', pode contribuir para reforçar uma estrutura social crescentemente excludente e injusta, mas pode também contribuir para lhe resistir.

O interesse deste livro é, portanto, significativo, porque pode ajudar a conscientizar a nossa comunidade alargada de práticas, na esfera da educação de adultos, acerca dos limites e constrangimentos da transformação social, mas também acerca das possibilidades que um pensar global e crítico e um agir local e engajado podem atingir.

\section{Notas}

1 Ver Nylander, E. (2010). Book Review. European Journal for Research on the Education and Learning of Adults, Vol. 1, No.1-2, pp. 147-149.

2 Ver Barros, R. (2009). Políticas para a Educação de Adultos em Portugal - A Governação Pluriescalar da "Nova Educação e Formação de Adultos» (19962006). Braga: Universidade do Minho [Tese de Doutoramento]. 